Research Article

\title{
Hydrothermal Preparation of $\mathrm{Ag} / \mathrm{Ag}_{1.69} \mathrm{Sb}_{2.27} \mathrm{O}_{6.25}$ Sesame-Hollow-Ball-Type Nanocomposites: The Formation Mechanism of Metallic Ag in the Ag- $\mathrm{H}_{2} \mathrm{O}$ System at $400 \mathrm{~K}$
}

\author{
Haomei Liu $\mathbb{D}$, ${ }^{1}$ Xihai Hao $\left(\mathbb{D},{ }^{1}\right.$ Yuejun Liu $\mathbb{D}$, ${ }^{1}$ and Aiguo Yan $\mathbb{D}^{2}$ \\ ${ }^{1}$ College of Packaging and Materials Engineering, Hunan University of Technology, Zhuzhou 412000, China \\ ${ }^{2}$ School of Materials Science and Engineering, Xiamen University of Technology, Xiamen 361024, China \\ Correspondence should be addressed to Yuejun Liu; yjliu_2005@126.com and Aiguo Yan; 754601094@qq.com
}

Received 30 July 2020; Revised 21 October 2020; Accepted 13 November 2020; Published 30 November 2020

Academic Editor: Sakar Mohan

Copyright (c) 2020 Haomei Liu et al. This is an open access article distributed under the Creative Commons Attribution License, which permits unrestricted use, distribution, and reproduction in any medium, provided the original work is properly cited.

$\mathrm{Ag} / \mathrm{Ag}_{1.69} \mathrm{Sb}_{2.27} \mathrm{O}_{6.25}$ sesame-hollow-ball-type nanocomposites were prepared via a facile one-step hydrothermal method at $400 \mathrm{~K}$. Power X-ray diffraction analysis shows that all diffraction peaks were well consistent with JCPDS card no: 89-6552 of $\mathrm{Ag}_{1.69} \mathrm{Sb}_{2.27} \mathrm{O}_{6.25}$. Scanning electron microscopy and high-resolution transmission electron microscopy images of the composites indicate that some smaller metallic Ag particles with size $18.3 \mathrm{~nm}$ uniformly dense on the surface of $\mathrm{Ag}_{1.69} \mathrm{Sb}_{2.27} \mathrm{O}_{6.25}$ hollow nanospheres with a mean size of about $170 \mathrm{~nm}$, producing $\mathrm{Ag} / \mathrm{Ag}_{1.69} \mathrm{Sb}_{2.27} \mathrm{O}_{6.25}$ hollow-sesame-ball nanocomposites. The surface chemical state of $\mathrm{Ag} / \mathrm{Ag}_{1.69} \mathrm{Sb}_{2.27} \mathrm{O}_{6.25}$ is investigated by XPS, and all peaks of $\mathrm{Ag} 3 \mathrm{~d}, \mathrm{O} 1 \mathrm{~s}$, and $\mathrm{Sb} 3 \mathrm{~d}$ show their different chemical states. The BET surface area of the sample is $7.268 \mathrm{~m}^{2} / \mathrm{g}$, and the pore sizes of nanocomposites are more than $5 \mathrm{~nm}$. The light absorption property of as-prepared materials is studied by UV-vis/DRS, and the adsorption band is located at $445 \mathrm{~nm}$, and the estimated energy band gap (Eg) is $2.55 \mathrm{eV}$. The calculated partial $\varphi-\mathrm{pH}$ diagrams in the $\mathrm{Ag}-\mathrm{H}_{2} \mathrm{O}$ system at $400 \mathrm{~K}$ predict that the $\mathrm{Ag}^{+}$ion can react with $\mathrm{H}_{2}$ to form metallic $\mathrm{Ag}$.

\section{Introduction}

The fabrication of silver antimonite nanoparticles has been intensively investigated in recent years due to their high electron mobility and photocatalytic activity, which are technological applications in visible-light-sensitive photocatalysts [1-5]. Due to the conduction band bottom mainly comprised of the hybridized hybridized $\mathrm{Ag} 5 \mathrm{~s}$ and $\mathrm{Sb} 5 \mathrm{~s}$ orbitals and the valence band top of Ag $4 \mathrm{~d}$ and O 2p, silver antimonite was reported to possess higher visible-light sensitivity compared with Ag-containing d-block metal complex oxides such as $\mathrm{AgNbO}_{3}$ and $\mathrm{AgVO}_{3}[6,7]$. However, the single-phase silver antimonites have quite low reduction potential and suffer from the easy recombination of photogenerated electrons and holes. Combining two semiconductors to construct silver antimonite-based heterostructure photocatalysts such as $\mathrm{AgSbO}_{3} / \mathrm{NaNbO}_{3}$ [8] and $\mathrm{AgSbO}_{3} / \mathrm{AgNbO}_{3}[9]$ and designing a " $Z$-scheme" such as $\mathrm{AgSbO}_{3} / \mathrm{Ag} / \mathrm{g}-\mathrm{C}_{3} \mathrm{~N}_{4}$ [10] have been considered to be efficient methods to prepare photocatalysts for producing enhanced photocatalytic activity.

In contrast to the above process, visible-light-triggered plasmonic photocatalysts have been recognized as another promising alternative to the traditional photocatalysts [11]. In these metal-semiconductor composites, metal nanoparticles (NPs) can strongly absorb visible light due to the surface plasmon resonance (SPR) effect and facilitate the separation of $e_{\mathrm{CB}}^{-}$and $h_{\mathrm{VB}}^{-}$generated on the semiconductor [12]. Recently, it has been reported that many semiconductors modified by nanosized noble metals such as $\mathrm{Au}$ enhance the overall photocatalytic efficiency due to their unique surface plasmon resonance (SPR) features originating from the collective oscillations of the electrons on the surface of the NPs. For example, Haruta and coworkers $[13,14]$ demonstrated that gold nanoparticles in the $2-5 \mathrm{~nm}$ range show unusually high catalytic activities. As a cheap 
noble metal, some studies about Ag, selected as the mediator to shuttle the electrons between the two semiconductor components in the $Z$-scheme, have been reported [15-20], but relative reports about Ag-based metal-semiconductor, especially Ag/Ag antimonite composites, were quietly scarce. And few researchers investigated about the mechanism of reduction of silver ions to metallic silver in the aqueous system.

In the present study, we have prepared sesame-hollowball-type $\mathrm{Ag} / \mathrm{Ag}_{1.69} \mathrm{Sb}_{2.27} \mathrm{O}_{6.25}$ nanocomposites through a simple one-step hydrothermal method. The mechanism of reduction of $\mathrm{Ag}^{+}$to $\mathrm{Ag}$ in the hydrometallurgy system on the basis of the partial potential-pH diagram for the silver-water system at a higher temperature of $400 \mathrm{~K}$ is investigated. This work will result in a general and economic synthetic strategy for obtaining various Ag-based semiconductors and a better understanding of the mechanism of their formation.

\section{Experimental Sections}

2.1. Materials. Potassium pyroantimonate $\left(\mathrm{KSbO}_{6} \mathrm{H}_{6}\right)$ was purchased from Xilong Scientific Co., Ltd. (China). $\mathrm{AgNO}_{3}$ was obtained from Xilong Scientific Co., Ltd. (China). All chemical reagents are of analytic grade without further purification. Deionized water was prepared with ultrapure water of 18.2 M $\Omega$ (Milli-Q, Millipore).

2.2. Preparation of Sesame-Ball-Type $\mathrm{Ag} / \mathrm{Ag}_{1.69} \mathrm{Sb}_{2.27} \mathrm{O}_{6.25}$ Hollow Nanocomposites. Firstly, $1.0192 \mathrm{~g}(3.88 \mathrm{mmol})$ of $\mathrm{KSbO}_{6} \mathrm{H}_{6}$ was dispersed in $50 \mathrm{~mL}$ deionized water and was kept stirring at $80^{\circ} \mathrm{C}$ for $0.5 \mathrm{~h}$. Secondly, $0.6796 \mathrm{~g}(4.0 \mathrm{mmol})$ of $\mathrm{AgNO}_{3}$ was dissolved in $5 \mathrm{~mL}$ deionized water and was slowly added into the above mixture and then kept stirring for 5 minutes. Thirdly, the mixture ( $\mathrm{pH}$ value is 6.8 measured using a $\mathrm{pH}$ meter) was sealed in a teflon-lined stainless-steel autoclave $\left(100 \mathrm{ml}\right.$ capacity) and heated at $127^{\circ} \mathrm{C}(400 \mathrm{~K})$ for $24 \mathrm{~h}$. After the reaction, the autoclave was cooled down to room temperature naturally. After washing (with deionized water and $99.5 \%$ ethanol) and drying (at $70^{\circ} \mathrm{C}$ for $3 \mathrm{~h}$ ), the sample was obtained.

2.3. Characterization. The obtained samples were characterized on a Bruker D8 Advance X-ray powder diffractometer (XRD) with $\mathrm{Cu}-\mathrm{K} \alpha$ radiation $(\lambda=1.5418 \AA)$. The size and morphology of the as-synthesized products were determined by a Zeiss Gemini 500 scanning electron microscope (SEM). High-resolution transmission electron microscopy (HRTEM) images were collected by JEOL JEM2010. The chemical state of samples was investigated by $\mathrm{X}$-ray photoelectron spectroscopy (XPS). UV-visible diffuse reflectance spectra were obtained on the Shimadzu UV-2600 spectrophotometer.

\section{Results and Discussion}

3.1. Characterizations of the $\mathrm{Ag} / \mathrm{Ag}_{1.69} \mathrm{Sb}_{2.27} \mathrm{O}_{6.25}$ Sesame-BallType Hollow Nanocomposites. The phase and crystal structures of the as-prepared sample were analyzed by XRD, and the result is shown in Figure 1. All diffraction peaks are well consistent with JCPDS card no: 89-6552 of $\mathrm{Ag}_{1.69} \mathrm{Sb}_{2.27} \mathrm{O}_{6.25}$, and the intense diffraction peak at $2 \theta=30.0^{\circ}$ is corresponding to the (222) plane. Compared to the peaks of Ag/ $\mathrm{Ag}_{1.69} \mathrm{Sb}_{2.27} \mathrm{O}_{6.25}$, the peak of metallic $\mathrm{Ag}$ is not observed, which may be due to that the amount of silver particles is too low to detect by XRD [15].

Figure 2 shows SEM images of $\mathrm{Ag} / \mathrm{Ag}_{1.69} \mathrm{Sb}_{2.27} \mathrm{O}_{6.25}$ composites. As shown in Figure 2(a), it could be found that the $\mathrm{Ag} / \mathrm{Ag}_{1.69} \mathrm{Sb}_{2.27} \mathrm{O}_{6.25}$ composites exhibit a sphere-type structure with a diameter of about $170 \mathrm{~nm}$, and there exist many broken spheres, which show that they are hollow inside. Figure 2(b) is a higher-magnification SEM image obtained from a selected area of Figure 2(a). Herein, a large number of smaller particles uniformly dispersing on the surface of the hollow nanospheres can be clearly observed. The whole shape of the nanocomposites looks like a Chinese delicacy hollow-sesame-ball. The subtle structure and composition of the sesame-ball-type hollow particles were further investigated by HRTEM. Figure 2(c) shows the HRTEM image obtained from a partial area of an individual hollow sphere. There are two smaller spheres, identified as "a" and "b," respectively, with size average $18.3 \mathrm{~nm}$ embedded in the particle. The crystal lattice of the "a" sphere is measured as $0.23 \mathrm{~nm}$, which is corresponding to (111) lattice planes of metal Ag. Besides for Ag, there is an interplanar distance of $0.3 \mathrm{~nm}$ which can be observed on the individual hollow sphere, which is identical with the (222) face of silver antimonite. The elemental distribution of the silver/silver antimonite is verified by the EDS elemental mapping, as illustrated in Figure 2(d), and suggests that there exist Sb, O, Ag elements of these broken hollow spheres but with only Ag and without $\mathrm{Sb}$ and $\mathrm{O}$ of all the smaller nanospheres, indicating that Ag nanoparticles embed into the $\mathrm{Ag}_{1.69} \mathrm{Sb}_{2.27} \mathrm{O}_{6.25}$ hollow sphere to form a hollow-sesameball.

The surface chemical state of $\mathrm{Ag} / \mathrm{Ag}_{1.69} \mathrm{Sb}_{2.27} \mathrm{O}_{6.25}$ was investigated by XPS. The detailed XPS spectrum of Ag $3 \mathrm{~d}$ in Figure 3(a) shows four peaks assigned to $\mathrm{Ag}^{+}$and $\mathrm{Ag}^{0}$, respectively. The peaks of $\mathrm{Ag} 3 \mathrm{~d}$ at round $373.9 \mathrm{eV}$ and $368.0 \mathrm{eV}$ are assigned to $\mathrm{Ag}^{+}$corresponding to $\mathrm{Ag} 3 \mathrm{~d}_{3 / 2}$ and $\mathrm{Ag} 3 \mathrm{~d}_{5 / 2}$, respectively, whereas the peaks at round $373.3 \mathrm{eV}$ and $367.9 \mathrm{eV}$ are assigned to $\mathrm{Ag}^{0}$, suggesting the existence of metallic Ag $[10,20]$. The O 1s XPS spectrum in Figure 3(b) shows two peaks at $530.4 \mathrm{eV}$ and $530.8 \mathrm{eV}$. The former peak of $530.4 \mathrm{eV}$ is derived from crystal lattice oxygen of $\mathrm{Ag} / \mathrm{Ag}_{1.69} \mathrm{Sb}_{2.27} \mathrm{O}_{6.25}$, and the latter one comes from hydroxyl [10]. Figure 3(c) shows the Sb 3d XPS spectrum, and it consists of three fitted peaks. The peaks at round $530.4 \mathrm{eV}$ and $530.5 \mathrm{eV}$ are assigned to oxygen in the form of $\mathrm{Sb}^{3+}$ and $\mathrm{Sb}^{5+}$, and the peak of $539.8 \mathrm{eV}$ corresponds to antimony-bonded silver [10]. All peaks of $\mathrm{Ag} \mathrm{3d}, \mathrm{O}$ 1s, and $\mathrm{Sb} 3 \mathrm{~d}$ show their different chemical states, revealing the hydrothermal synthesis mechanism of $\mathrm{Ag} / \mathrm{Ag}_{1.69} \mathrm{Sb}_{2.27} \mathrm{O}_{6.25}$.

Figure 4 shows the $\mathrm{N}_{2}$ adsorption-desorption curves for $\mathrm{Ag} / \mathrm{Ag}_{1.69} \mathrm{Sb}_{2.27} \mathrm{O}_{6.25}$ nanocomposites, and the characteristics of the adsorption curve are a classic second kind of physical adsorption curve [21] in which the adsorption 


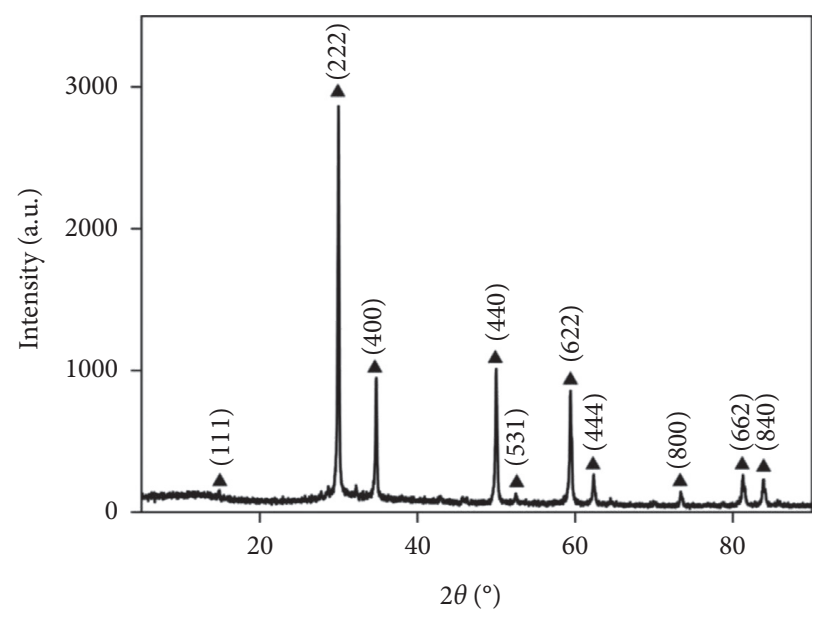

\ $\mathrm{Ag}_{1.19} \mathrm{O}_{6.13} \mathrm{Sb}_{2.36}$

FIGURE 1: XRD patterns of $\mathrm{Ag} / \mathrm{Ag}_{1.69} \mathrm{Sb}_{2.27} \mathrm{O}_{6.25}$ hollow-sesame-ball nanocomposites.

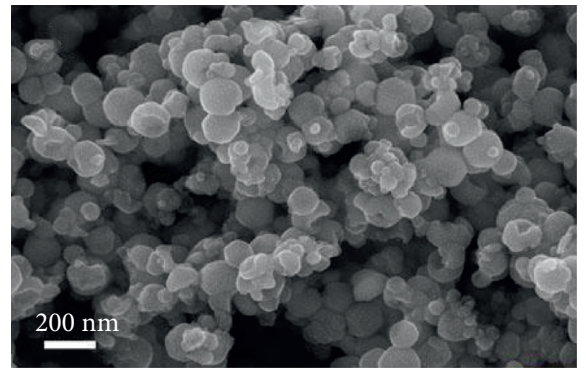

(a)
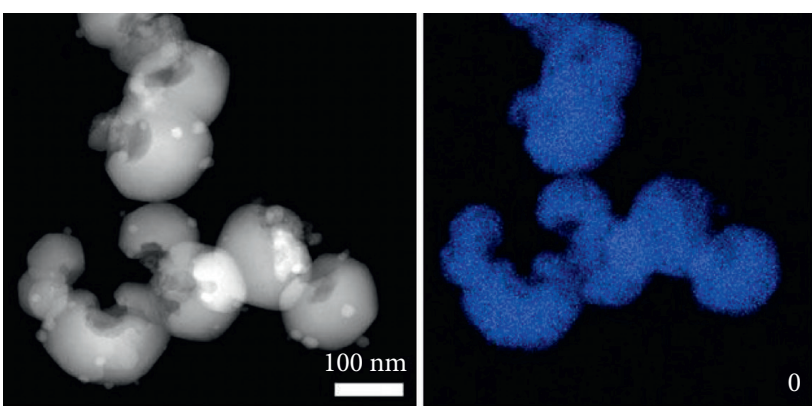

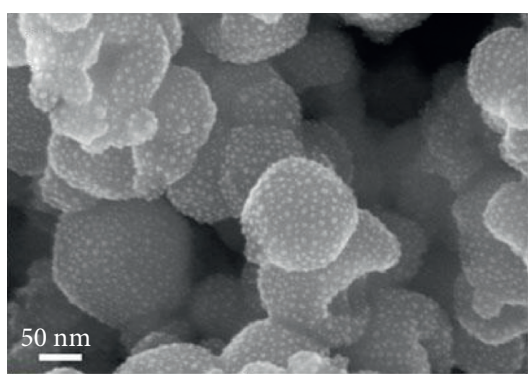

(b)

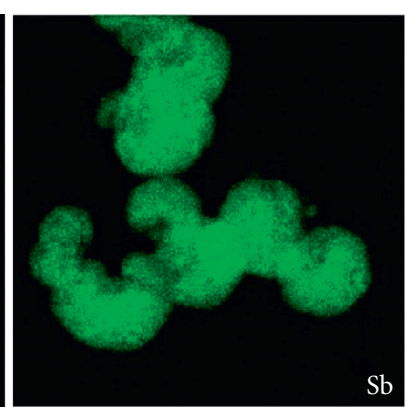

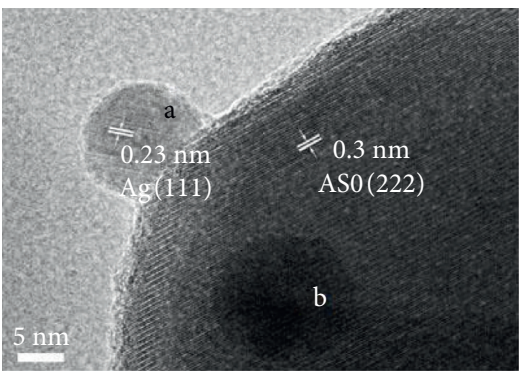

(c)

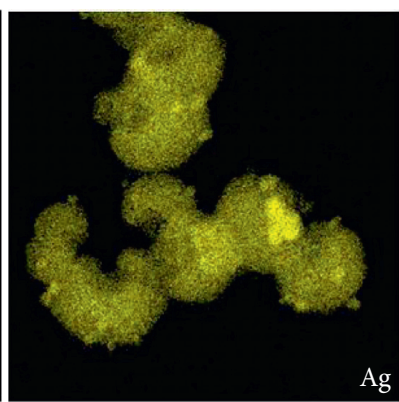

(d)

Figure 2: (a) SEM. (b) High-magnification SEM. (c) HRTEM. (d) EDS elemental mapping images of Ag/ $\mathrm{Ag}_{1.69} \mathrm{Sb}_{2.27} \mathrm{O}_{6.25}$ hollow-sesameball nanocomposites.

capacity increases slowly in the first half of the isotherm, showing an upward convex shape, and then violently increases in the second half of the one. The BET surface area of the as-fabricated sample is $7.268 \mathrm{~m}^{2} / \mathrm{g}$, and the pore sizes of nanoparticles, investigated by the $\mathrm{BJH}$ model (see the inset), are more than $5 \mathrm{~nm}$.

The light absorption property of as-prepared materials was studied by UV-vis/DRS, and the result is shown in Figure 5 in which the adsorption band is located at $445 \mathrm{~nm}$, and the estimated energy band gap ( $\mathrm{Eg})$ is $2.55 \mathrm{eV}$ according to the following formula:

$$
\alpha h v=A\left(h v-E_{g}\right)^{1 / 2},
$$

where $E_{g}, h, \alpha, v$, and $A$ are the band gap, plank constant, absorption coefficient, light frequency, and constant, respectively.

3.2. The Formation Mechanism of the $\mathrm{Ag} / \mathrm{Ag}{ }_{1.69} \mathrm{Sb}_{2.27} \mathrm{O}_{6.25}$ Sesame-Ball-Type Hollow Nanocomposites. The mechanism leading to the formation of the $\mathrm{Ag} / \mathrm{Ag}_{1.69} \mathrm{Sb}_{2.27} \mathrm{O}_{6.25}$ sesameball-type hollow nanocomposites is not yet clear. However, 


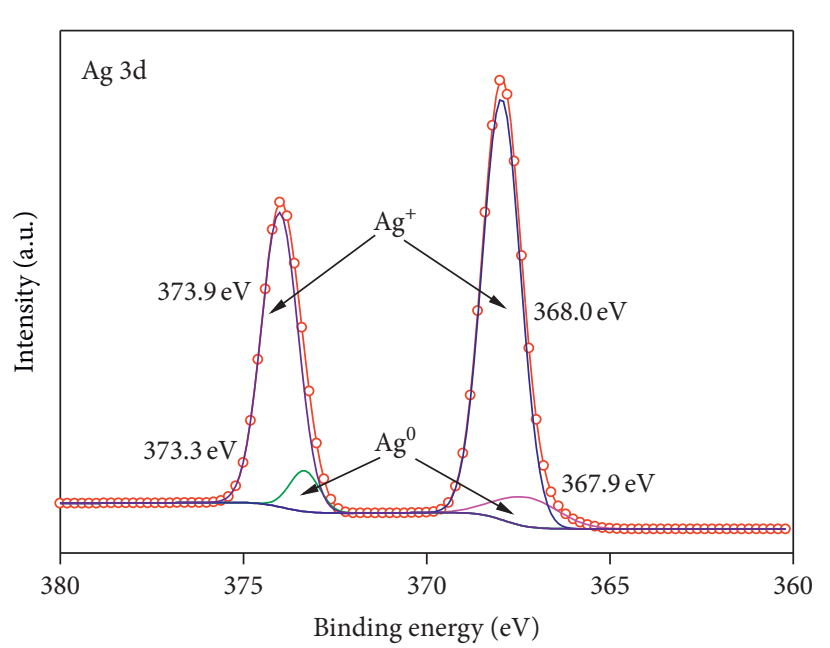

(a)

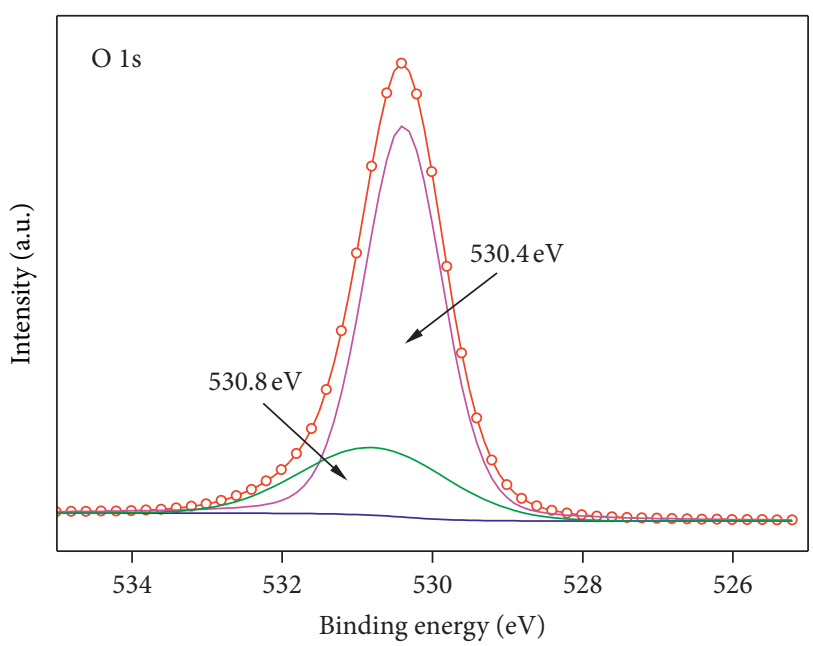

(b)

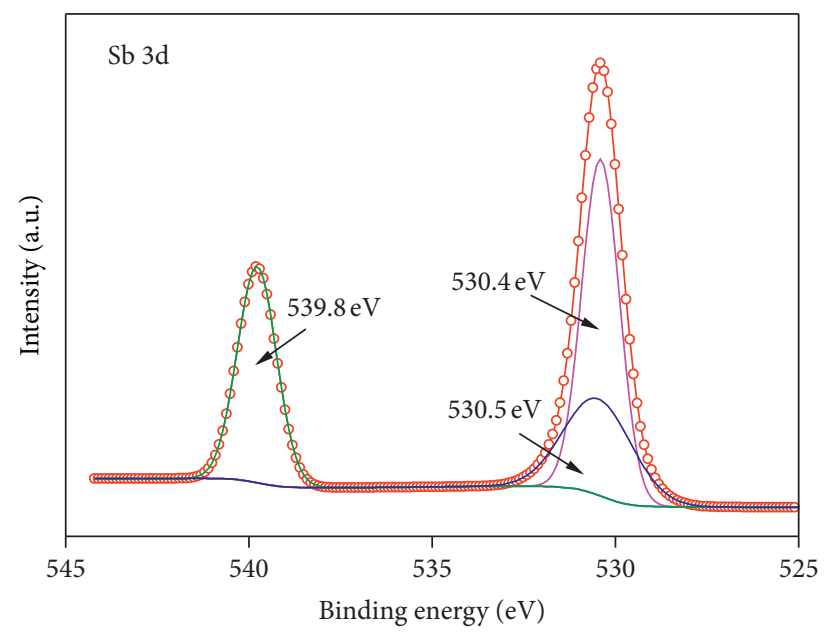

(c)

Figure 3: XPS patterns of $\mathrm{Ag} / \mathrm{Ag}_{1.69} \mathrm{Sb}_{2.27} \mathrm{O}_{6.25}$ hollow-sesame-ball nanocomposites. (a) $\mathrm{Ag} \mathrm{3d}$. (b) O 1s. (c) Sb 3d.

our own experimental evidence has led us to believe the formation process of $\mathrm{Ag} / \mathrm{Ag}_{1.69} \mathrm{Sb}_{2.27} \mathrm{O}_{6.25}$, schematically illustrated in Figure 6. Firstly, potassium pyroantimonate and silver nitrate are separately dissociated into $\mathrm{S}_{\mathrm{b}} \mathrm{O}_{6} \mathrm{H}_{6}^{-}$and $\mathrm{K}^{+}$(equation (2)) and $\mathrm{Ag}^{+}$and $\mathrm{NO}_{3}^{-}$(equation (3)) in warm aqueous solution. Lots of tiny $\mathrm{Ag}_{1.69} \mathrm{Sb}_{2.27} \mathrm{O}_{6.25}$ crystal nuclei are formed by the reaction between $\mathrm{S}_{\mathrm{b}} \mathrm{O}_{6} \mathrm{H}_{6}^{-}$and $\mathrm{Ag}^{+}$ (equation (4)) and preferentially adsorbed on the gas-liquid interface on the bubbles, produced in the boiling aqueous in the reclusive reactor at $400 \mathrm{~K}$, because of the enhanced surfce tension of gas-liquid interface layer by the presence of inorganic ions such as $\mathrm{K}^{+}$and $\mathrm{NO}_{3}^{-}$[21].

$$
\begin{gathered}
\mathrm{KSbO}_{6} \mathrm{H}_{6}=\mathrm{SbO}_{6} \mathrm{H}_{6}{ }^{-}+\mathrm{K}^{+} \\
\mathrm{AgNO}_{3}=\mathrm{NO}_{3}{ }^{-}+\mathrm{Ag}^{+} \\
\mathrm{SbO}_{6} \mathrm{H}_{6}{ }^{-}+\mathrm{Ag}^{+} \longrightarrow \mathrm{Ag}_{1.69} \mathrm{Sb}_{2.27} \mathrm{O}_{6.25} \downarrow
\end{gathered}
$$

Then, the generated $\mathrm{Ag}_{1.69} \mathrm{Sb}_{2.27} \mathrm{O}_{6.25}$ nucleus grows upon the ball-type interface on the bubbles and forms hollow-sphere-structure $\mathrm{Ag}_{1.69} \mathrm{Sb}_{2.27} \mathrm{O}_{6.25}$ nanoparticles. Metallic Ag nanoparticles, with size average $18.3 \mathrm{~nm}$, which were reduced from $\mathrm{Ag}+$ in the hydrothermal reaction system, gather on the surface of Ag1.69Sb2.27O6.25 hollow-sphere to form sesame-hollow-ball-type nanocomposites.

3.3. The Formation Mechanism of $\mathrm{Ag}$ in the Silver-Water System at $400 \mathrm{~K}$. Recently, the fabrication and photocatalytic activity of Ag-based composites including Ag-containing multimetal oxides such as $\mathrm{AgMO}_{2}(\mathrm{M}=\mathrm{Al}, \mathrm{Cr})$ [22], $\mathrm{AgGaO}_{2}$ [23], and $\mathrm{AgSbO}_{3}$ [11] and the hierarchical Zscheme photocatalysts such as $\mathrm{g}-\mathrm{C}_{3} \mathrm{~N}_{4} @ \mathrm{Ag} / \mathrm{BiVO}_{4}$ [24], $\mathrm{Ag} @ \mathrm{AgBr} / \mathrm{g}-\mathrm{C}_{3} \mathrm{~N}_{4}$ [15], and $\mathrm{Ag}_{2} \mathrm{CrO}_{4} / \mathrm{Ag} / \mathrm{g}-\mathrm{C}_{3} \mathrm{~N}_{4}$ [20], in which metallic $\mathrm{Ag}$ is used as an electron mediator, have been intensively investigated. In these studies, the action and 


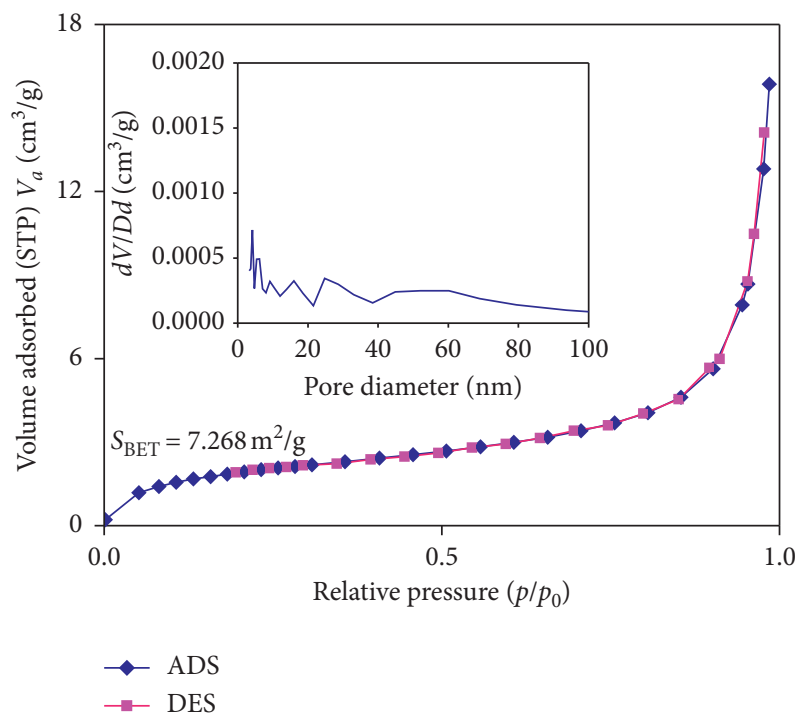

FIGURE 4: Nitrogen adsorption-desorption isotherms for $\mathrm{Ag} / \mathrm{Ag}_{1.69} \mathrm{Sb}_{2.27} \mathrm{O}_{6.25}$ hollow-sesame-ball nanocomposites (inset, pore size distributions).

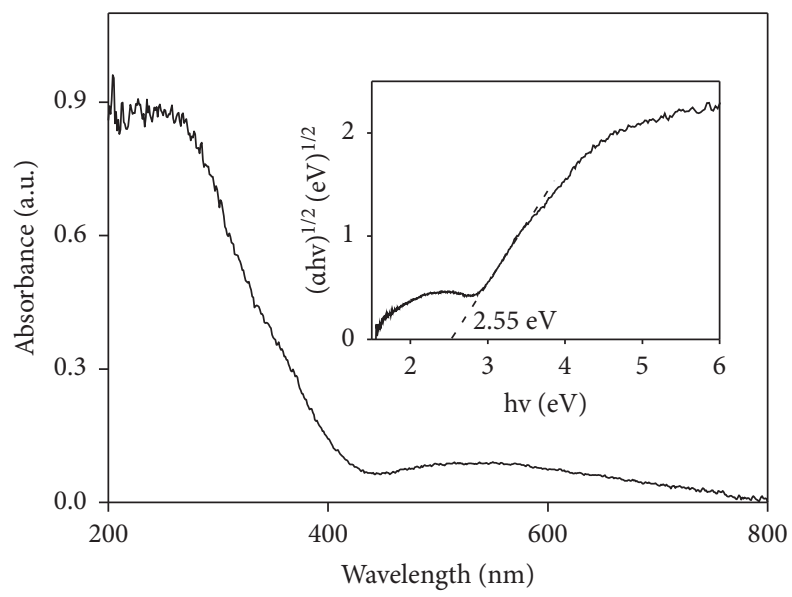

FIGURE 5: UV-vis DRS light adsorption spectra and band gap calculation diagram of $\mathrm{Ag} / \mathrm{Ag}_{1.69} \mathrm{Sb}_{2.27} \mathrm{O}_{6.25}$.

mechanism of metallic silver have been fully studied. However, few researchers investigate the formation mechanism of reduction of silver ions, dissociated fromation silver nitrate, to silver in the hydrometallurgy system at $400 \mathrm{~K}$. In the search, we construct the partial potential-pH diagram based on the thermodynamic calculation of the aqueous solution at $400 \mathrm{~K}$ and standard pressure $\left(1 \mathrm{p}^{\Theta}\right)$ and reveal that when the $\mathrm{pH}$ value is 6.8 , the oxidant $\mathrm{Ag}^{+}$ion can react with the reductant $\mathrm{H}_{2}$ to form $\mathrm{Ag}$ and $\mathrm{H}^{+}$ion.

3.3.1. Thermodynamic Calculations. The following half-cell reaction represents a general electrochemical reaction in the hydrothermal reaction system [25]:

$$
\mathrm{aA}+\mathrm{mH}^{+}+\mathrm{ze}^{-}=\mathrm{bB}+\mathrm{cH}_{2} \mathrm{O}
$$

where $\mathrm{a}, \mathrm{m}, \mathrm{b}$, and $\mathrm{c}$ are the stoichiometric coefficients for species $\mathrm{A}, \mathrm{H}^{+}, \mathrm{B}$, and $\mathrm{H}_{2} \mathrm{O}$ in the electrochemical reaction, respectively, and $\mathrm{z}$ is the electron transfer number of the electrode reaction. In the dilute solution, when $\mathrm{a}_{\mathrm{H} 2 \mathrm{O}}=1$ for the activity of water, the equilibrium potential can be simplified as follows according to the Nernst equation:

$$
\varphi(T)=\varphi^{\Theta}(T)-\frac{2.30 R \operatorname{Tm}}{z F} \mathrm{pH}-\frac{2.30 R \operatorname{Tm}}{z F} \lg \left(\frac{a_{B}^{b}}{a_{A}^{a}}\right),
$$

where $\varphi(T)$ or $\varphi^{\Theta}(T)$ is the electrochemical potential or standard electrochemical potential for the reaction at a certain temperature $T ; F$ is Faraday's constant; $R$ is the molar gas constant; and $a_{A}$ or $a_{B}$ is the overall activity of species $A$ or $B$.

The relationship between $\varphi^{\Theta}(T)$ and standard free energy of the reaction in equation (5) is shown explicitly: 


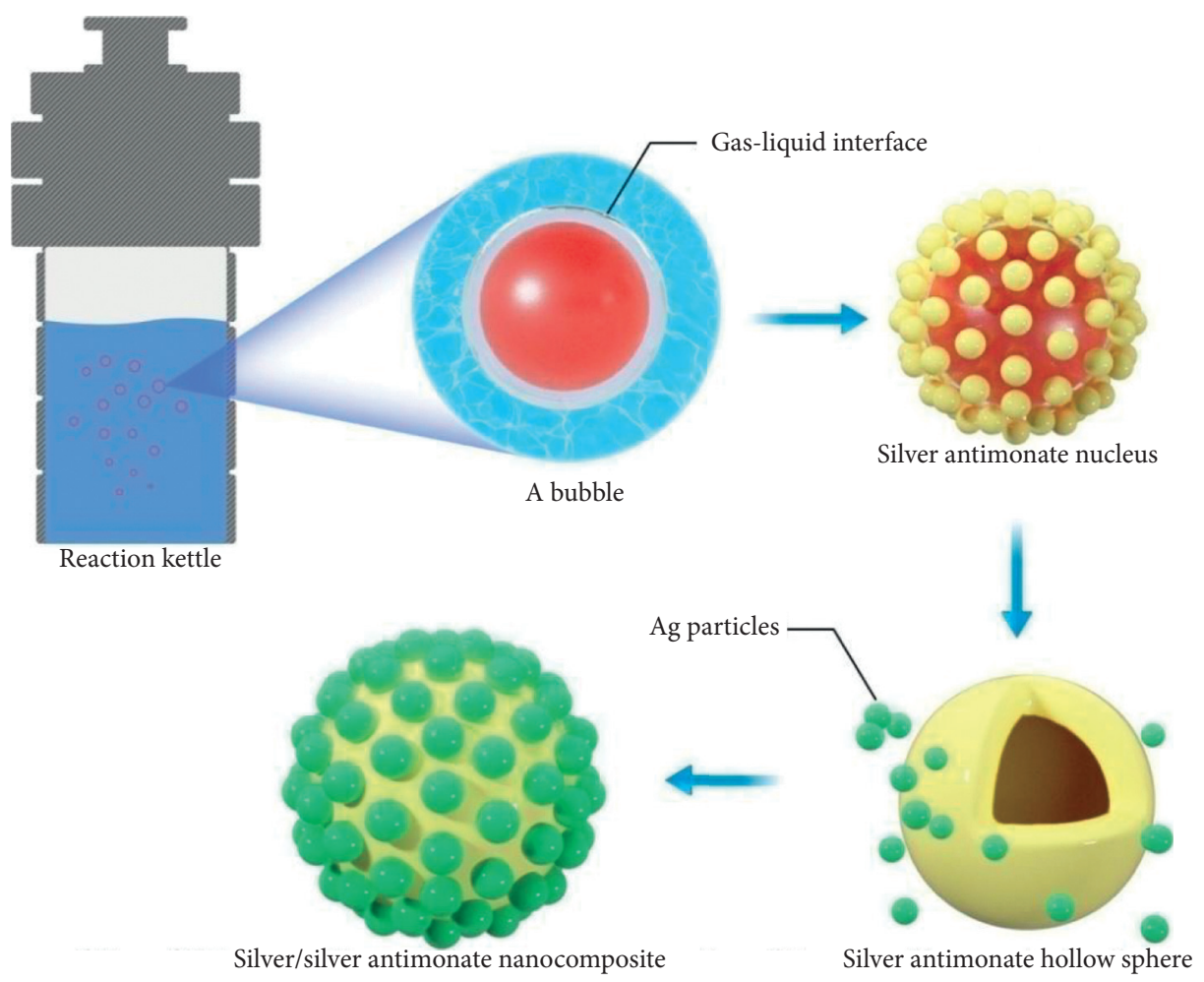

FIgURE 6: Schematic illustration for the formation process of $\mathrm{Ag} / \mathrm{Ag}_{1.69} \mathrm{Sb}_{2.27} \mathrm{O}_{6.25}$ sesame-hollow-ball-type nanocomposites.

$$
\Delta_{r} G_{m}^{\Theta}(T)=-z F \varphi^{\Theta}(T)
$$

where $\Delta_{r} G_{m}^{\Theta}(T)$ is the standard molar free energy of the reaction at temperature $T$.

At arbitrary temperature and standard pressure, the thermodynamic parameters including $\Delta_{r} H_{m}^{\Theta}(T), \Delta_{r} S_{m}^{\Theta}(T)$, and $\Delta_{r} G_{m}^{\Theta}(T)$ of general electrochemical reaction (5) are calculated through the relationship as follows:

$$
\begin{aligned}
\Delta_{r} H_{m}^{\Theta}(T) & =\Delta_{r} H_{m}^{\Theta}(298 \mathrm{~K})+\int_{298}^{T} \Delta_{r} C_{P}(T) d T \\
& =\sum_{B} v_{B} \Delta_{f} H_{m}^{\Theta}(B, 298 \mathrm{~K})+\int_{298}^{T} \sum_{B} v_{B} C_{p, m}^{\Theta}(B, T) d T,
\end{aligned}
$$

where $\triangle_{f} H_{m}^{\Theta}(B, 298 \mathrm{~K})$ is the standard enthalpy of formation of substance $B ; \Delta_{r} H_{m}^{\Theta}(298 \mathrm{~K})$ or $\Delta_{r} H_{m}^{\Theta}(T)$ is the molar reaction enthalpy of the reaction at $298 \mathrm{~K}$ or temperature $T / \mathrm{K}$ under the same standard pressure; $C_{p, m}^{\Theta}(B, T)$ or $\Delta_{r} C_{p}^{\Theta}(T)$ is the standard heat capacity at standard pressure of substance $B$ or the reaction at temperature $T$; and $\nu_{B}$ is the stoichiometry of substance $B$, and $\nu_{B}$ is positive for the reactant and negative for the product.

$$
\begin{aligned}
\Delta_{r} S_{m}^{\Theta}(T) & =\Delta_{r} S_{m}^{\Theta}(298 \mathrm{~K})+\int_{298 \mathrm{~K}}^{T} \frac{\sum_{B} v_{B} C_{P, m}(B) d T}{T} \\
& =\sum_{B} v_{B} S_{m}(B, 298 \mathrm{~K})+\int_{298 K}^{T} \frac{\sum_{B} v_{B} C_{P, m}(B) d T}{T},
\end{aligned}
$$

where $S_{m}^{\Theta}(B, 298 \mathrm{~K})$ is the third law entropy of substance $B$ at $298 \mathrm{~K} ; \Delta_{r} S_{m}^{\Theta}(298 \mathrm{~K})$ or $\Delta_{r} S_{m}^{\Theta}(T)$ is the molar reaction entropy of the reaction at $298 \mathrm{~K}$ or temperature $T / \mathrm{K}$ under the same standard pressure.

$$
\Delta_{r} G_{m}^{\Theta}(T)=\Delta_{r} H_{m}^{\Theta}(T)-T \Delta_{r} S_{m}^{\Theta}(T) .
$$

The data of the thermodynamic calculation in this paper are obtained from [26], except as otherwise indicated, and the thermodynamic data of the main substances in the Ag$\mathrm{H}_{2} \mathrm{O}$ system are listed in Table 1 .

In Table $1, \Delta_{f} H_{m}^{\Theta}(298 \mathrm{~K})$ is the standard enthalpy of formation at $298 \mathrm{~K} ; S_{m}^{\Theta}(298 \mathrm{~K})$ is the third law entropy at $298 \mathrm{~K}$; and $C_{p, m}^{\Theta}(298 \mathrm{~K})$ is the standard heat capacity at standard pressure at $298 \mathrm{~K}$.

3.3.2. The Partial Potential-pH Diagrams. The partially relevant reactions are listed in Table 2 . The diagrams for other values of activity and pressure can be easily obtained by $\mathrm{pH}$-potential functions listed in Table 2 . The partial potential-pH diagrams of the $\mathrm{Ag}-\mathrm{H}_{2} \mathrm{O}$ system are plotted in Figure 7. It can be seen that when the $\mathrm{pH}$ value is 6.8 (lower than 7.0), the line of $\mathrm{Ag}^{+} / \mathrm{Ag}$ equilibrium is higher than $\mathrm{H}^{+} / \mathrm{H}_{2}$ equilibrium which means that, in these two electric pairs, the stronger oxidant $\mathrm{Ag}^{+}$ion can react with the stronger reductant $\mathrm{H}_{2}$ to form the weaker reductant $\mathrm{Ag}$ and the weaker oxidant $\mathrm{H}^{+}$:

$$
2 \mathrm{Ag}^{+}+\mathrm{H}_{2}=\mathrm{Ag} \downarrow+2 \mathrm{H}^{+}
$$


TABle 1: Thermodynamic data of the main substances in the Ag- $\mathrm{H}_{2} \mathrm{O}$ system.

\begin{tabular}{lccc}
\hline Species & $\Delta_{f} H_{m}^{\Theta}(298 \mathrm{~K}) / \mathrm{kJ} \cdot \mathrm{mol}^{-1}$ & $S_{m}^{\Theta}(298 \mathrm{~K}) / \mathrm{J} \cdot \mathrm{mol}^{-1} \cdot \mathrm{K}^{-1}$ & $C_{p, m}^{\Theta}(298 \mathrm{~K}) / \mathrm{J} \cdot \mathrm{K}^{-1} \cdot \mathrm{mol}^{-1}$ \\
\hline $\mathrm{H}_{2(\mathrm{~g})}$ & 0 & 130.684 & 28.836 \\
$\mathrm{O}_{2(\mathrm{~g})}$ & 0 & 250.138 & 29.378 \\
$\mathrm{H}_{2} \mathrm{O}_{(\mathrm{l})}$ & -285.830 & 69.91 & 75.291 \\
$\mathrm{H}^{+}{ }_{(\mathrm{aq})}$ & 0 & 0 & 0 \\
$\mathrm{Ag}_{(\mathrm{s})}$ & 0 & 42.55 & 25.351 \\
$\mathrm{Ag}^{+}(\mathrm{aq})$ & -105.579 & 77.107 & 21.8 \\
\hline
\end{tabular}

TABLE 2: Electrode reactions and $\varphi$-pH equations.

\begin{tabular}{|c|c|c|}
\hline Electrode reactions & $\varphi$-pH equations & $\varphi^{\Theta}(400 \mathrm{~K})(\mathrm{V})$ \\
\hline $\mathrm{O}_{2}+4 \mathrm{H}^{+}+4 \mathrm{e}^{-}=2 \mathrm{H}_{2} \mathrm{O}$ & $\begin{aligned} \varphi(400 \mathrm{~K}) & =\varphi^{\Theta}(400 \mathrm{~K})-(2.303 R \times 400 / F) \mathrm{pH}-(2.303 R \times 400 / F) \lg \left(a_{H_{2} 0}^{2} /\left(p_{\mathrm{O}_{2}} / p^{\Theta}\right)\right) \\
& =1.418 \mathrm{~V}-0.0794 \mathrm{pH}\left(\text { when } a_{\mathrm{H}_{2} 0}=1 \text { and } p_{\mathrm{O}_{2}}=p^{\Theta}\right) .\end{aligned}$ & 1.418 \\
\hline $2 \mathrm{H}^{+}+2 \mathrm{e}^{-}=\mathrm{H}_{2}$ & $\begin{aligned} \varphi(400 \mathrm{~K}) & =\varphi^{\Theta}(400 \mathrm{~K})-(2.303 R \times 400 / F) \mathrm{pH}-(2.303 R \times 400 / F) \lg \left(p_{\mathrm{H}_{2}} / p^{\Theta}\right) \\
& =0.273 \mathrm{~V}-0.0794 \mathrm{pH}\left(\text { when } p_{\mathrm{H}_{2}}=p^{\Theta}\right)\end{aligned}$ & 0.273 \\
\hline $\mathrm{Ag}^{+}+\mathrm{e}^{-}=\mathrm{Ag}$ & $\begin{aligned} \varphi(400 \mathrm{~K}) & =\varphi^{\Theta}(400 \mathrm{~K})-(2.303 R \times 400 / F) \lg \left(C^{\Theta} / C_{A g}\right) \\
& =0.861 \mathrm{~V}\left(\text { when } C^{\Theta}=1.0 \mathrm{~mol} \cdot 1^{-1} \text { and } C_{\mathrm{Ag}}=0.07 \mathrm{~mol} \cdot \mathrm{l}^{-1}\right)\end{aligned}$ & 0.951 \\
\hline
\end{tabular}

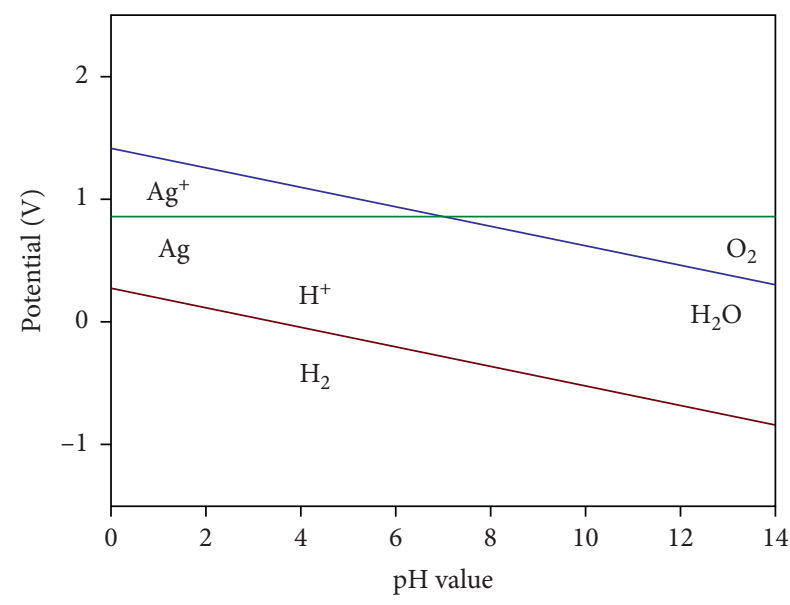

Figure 7: Partial potential-pH diagrams of the $\mathrm{Ag}-\mathrm{H}_{2} \mathrm{O}$ system at $400 \mathrm{~K}$.

\section{Conclusions}

In summary, a facile one-step hydrothermal method was developed to synthesize $\mathrm{Ag} / \mathrm{Ag}_{1.69} \mathrm{Sb}_{2.27} \mathrm{O}_{6.25}$ sesame-hollow-ball-type nanocomposites in large quantities at $400 \mathrm{~K}$. Structural characterization technique indicates that largequantity smaller, about $18.3 \mathrm{~nm}$, metallic Ag particles uniformly dense on the surface of $\sim 170 \mathrm{~nm} \mathrm{Ag}_{1.69} \mathrm{Sb}_{2.27} \mathrm{O}_{6.25}$ hollow nanospheres to form the novel $\mathrm{Ag} / \mathrm{Ag}_{1.69} \mathrm{Sb}_{2.27} \mathrm{O}_{6.25}$ hollow-sesame-ball nanocomposites. The calculated partial $\varphi$ - $\mathrm{pH}$ diagrams predicted that the $\mathrm{Ag}^{+}$ion can react with $\mathrm{H}_{2}$ to form $\mathrm{Ag}$ in the $\mathrm{Ag}-\mathrm{H}_{2} \mathrm{O}$ system at $400 \mathrm{~K}$, which will provide new deep insights into the silver-containing photocatalyst with enhanced photocatalytic activity.

\section{Data Availability}

The data used to support the findings of this study are available from the corresponding author upon request.

\section{Disclosure}

This research was performed at the Hunan University of Technology and Xiamen University of Technology.

\section{Conflicts of Interest}

The authors declare that they have no conflicts of interest.

\section{Authors' Contributions}

Haomei Liu organized the research and wrote the manuscript. Xihai Hao and Aiguo Yan provided the laboratory and apparatus. Yuejun Liu checked the manuscript and revised the manuscript according to the reviews' comments.

\section{Acknowledgments}

This research was funded by the National Natural Science Foundation of China (Grant no. 11872179).

\section{References}

[1] Z. Yi, J. Ye, N. Kikugawa et al., "An orthophosphate semiconductor with photooxidation properties under visible-light irradiation," Nature Materials, vol. 9, no. 7, pp. 559-564, 2010.

[2] T. Kako, N. Kikugawa, and J. Ye, "Photocatalytic activities of $\mathrm{AgSbO}_{3}$ under visible light irradiation," Catalysis Today, vol. 131, no. 1-4, pp. 197-202, 2008.

[3] J. Shi, J. Ye, Q. Li et al., "Single-crystal nanosheet-based hierarchical $\mathrm{AgSbO}_{3}$ with exposed $\{001\}$ facets: topotactic synthesis and enhanced photocatalytic activity," Chemistry- $A$ European Journal, vol. 18, no. 11, pp. 3157-3162, 2012.

[4] D. P. Chen, W. Bowers, and S. E. Skrabalak, "Aerosol-assisted combustion synthesis of single-crystalline $\mathrm{NaSbO}_{3}$ nanoplates: a topotactic template for ilmenite $\mathrm{AgSbO}_{3}$," Chemistry of Materials, vol. 27, no. 1, pp. 174-180, 2015.

[5] F. Li and J.-F. Li, "Microstructure and thermoelectric properties of $\mathrm{AgSbO}_{3}$ ceramics prepared by ion-exchange powder 
synthesis and normal sintering," Journal of Electronic Materials, vol. 40, no. 5, pp. 1035-1041, 2011.

[6] H. Kato, H. Kobayashi, and A. Kudo, "Role of $\mathrm{Ag}^{+}$in the band structures and photocatalytic properties of $\mathrm{AgMO}_{3}(\mathrm{M}$ : Ta and $\mathrm{Nb}$ ) with the perovskite structure," The Journal of Physical Chemistry B, vol. 106, no. 48, pp. 12441-12447, 2002.

[7] R. Konta, H. Kato, H. Kobayashi, and A. Kudo, "Photophysical properties and photocatalytic activities under visible light irradiation of silver vanadates," Physical Chemistry Chemical Physics, vol. 5, no. 14, pp. 3061-3065, 2003.

[8] G. Li, W. Wang, N. Yang, and W. F. Zhang, "Composition dependence of $\mathrm{AgSbO}_{3} / \mathrm{NaNbO}_{3}$ composite on surface photovoltaic and visible-light photocatalytic properties," Applied Physics A, vol. 103, no. 1, pp. 251-256, 2011.

[9] G. Li, Y. Bai, W. F. Zhang, and H. Zhang, "Enhanced visible light photocatalytic properties of $\mathrm{AgNbO}_{3} / \mathrm{AgSbO}_{3}$ composites," Materials Chemistry and Physics, vol. 139, no. 2-3, pp. 1009-1013, 2013.

[10] Z. Zheng, N. Zhang, T. Wang et al., " $\mathrm{Ag}_{1.69} \mathrm{Sb}_{2.27} \mathrm{O}_{6.25}$ coupled carbon nitride photocatalyst with high redox potential for efficient multifunctional environmental applications," $A p$ plied Surface Science, vol. 487, pp. 82-90, 2019.

[11] M. Xiao, R. Jiang, F. Wang, C. Fang, J. Wang, and J. C. Yu, "Plasmon-enhanced chemical reactions," Journal of Materials Chemistry A, vol. 1, no. 19, pp. 5790-5805, 2013.

[12] P. Wang, B. Huang, Y. Dai, and M.-H. Whangbo, "Plasmonic photocatalysts: harvesting visible light with noble metal nanoparticles," Physical Chemistry Chemical Physics, vol. 14, no. 28, pp. 9813-9825, 2012.

[13] G. R. Bamwenda, S. Tsubota, T. Kobayashi, and M. Haruta, "Photoinduced hydrogen production from an aqueous solution of ethylene glycol over ultrafine gold supported on $\mathrm{TiO}_{2}$," Journal of Photochemistry and Photobiology A: Chemistry, vol. 77, no. 1, pp. 59-67, 1994.

[14] M. Haruta, "Size-and support-dependency in the catalysis of gold," Catalysis Today, vol. 36, no. 1, pp. 3-166, 1997.

[15] Y. Yang, W. Guo, Y. Guo, X. Yuan, and Y. Guo, "Fabrication of Z-scheme plasmonic photocatalyst Ag@AgBr/g-C3N4 with enhanced visible-light photocatalytic activity," Journal of Hazardous Materials, vol. 271, pp. 150-159, 2014.

[16] W. Li, C. Feng, S. Dai, J. Yue, F. Hua, and H. Hou, "Fabrication of sulfur-doped g-C $3 \mathrm{~N}$ 4/Au/CdS Z-scheme photocatalyst to improve the photocatalytic performance under visible light," Applied Catalysis B: Environmental, vol. 168169, pp. 465-471, 2015.

[17] D. Ma, J. Wu, M. Gao, Y. Xin, T. Ma, and Y. Sun, "Fabrication of Z-scheme g-C 3 N 4/RGO/Bi 2 WO 6 photocatalyst with enhanced visible-light photocatalytic activity," Chemical Engineering Journal, vol. 290, pp. 136-146, 2016.

[18] Y. He, L. Zhang, B. Teng, and M. Fan, "New application of $\mathrm{Z}$-scheme $\mathrm{Ag}_{3} \mathrm{PO}_{4} / \mathrm{g}$-C3N4 composite in converting $\mathrm{CO}_{2}$ to fuel," Environmental Science \& Technology, vol. 49, no. 1, pp. 649-656, 2015.

[19] X. Yang, Z. Chen, J. Xu, H. Tang, K. Chen, and Y. Jiang, "Tuning the morphology of g-C3N4 for improvement of Z-scheme photocatalytic water oxidation," ACS Applied Materials \& Interfaces, vol. 7, no. 28, pp. 15285-15293, 2015.

[20] Y. Gong, X. Quan, H. Yu, and S. Chen, "Synthesis of Z-scheme $\mathrm{Ag}_{2} \mathrm{CrO}_{4} / \mathrm{Ag} / \mathrm{g}-\mathrm{C} 3 \mathrm{~N} 4$ composite with enhanced visible-light photocatalytic activity for 2,4-dichlorophenol degradation," Applied Catalysis B: Environmental, vol. 219, pp. 439-449, 2017.
[21] X. C. Fu, W. X. Shen, T. Y. Yao, and W. H. Hou, "Physical chemistry (next volume)," Higher Education Press, vol. 27, pp. 358-391, 2006.

[22] S. Ouyang, Z. Li, Z. Ouyang, T. Yu, J. Ye, and Z. Zou, "Correlation of crystal structures, electronic structures, and photocatalytic properties in a series of Ag-based oxides: $\mathrm{AgAlO}_{2}, \mathrm{AgCrO}_{2}$, and $\mathrm{Ag}_{2} \mathrm{CrO}_{4}$," The Journal of Physical Chemistry C, vol. 112, no. 8, pp. 3134-3141, 2008.

[23] S. Ouyang, N. Kikugawa, D. Chen, Z. Zou, and J. Ye, "A systematical study on photocatalytic properties of $\mathrm{AgMO}_{2}$ $(\mathrm{M}=\mathrm{Al}, \mathrm{Ga}$, in): effects of chemical compositions, crystal structures, and electronic structures," The Journal of Physical Chemistry C, vol. 113, no. 4, pp. 1560-1566, 2009.

[24] M. Ou, S. Wan, Q. Zhong et al., "Hierarchical Z-scheme photocatalyst of g-C3N4@Ag/BiVO4 (040) with enhanced visible-light-induced photocatalytic oxidation performance," Applied Catalysis B: Environmental, vol. 221, pp. 97-107, 2018.

[25] H.-X. You, H.-B. Xu, Y. Zhang, S.-L. Zheng, and Y.-Y. Gao, "Potential-pH diagrams of $\mathrm{Cr}-\mathrm{H}_{2} \mathrm{O}$ system at elevated temperatures," Transactions of Nonferrous Metals Society of China, vol. 20, no. 1, pp. s26-s31, 2010.

[26] H. E. Barner and R. V. Scheuerman, Handbook of ThermoChemical Data for Compounds and Aqueous Species, John Willy \& Sons, New York, NY, USA, 1978. 